\title{
Production impact of parasitisms and coccidiosis in
} \section{swine}

\begin{abstract}
The internal and external parasites in swine might result in considerable economic losses. The external parasites, such as mites (sarcoptic mange), lice, flies, fleas and ticks, could have detrimental impact on production in either a direct or indirect way. The mange on average reduces the average daily gain (ADG) by $11 \%(1-29 \%)$ and deteriorates the feed conversion ratio (FCR) by $6 \%(2-10 \%)$ for fattening pigs. The house flies (Musca domestica) and stable flies (Stomoxys calcitrans) can cause $1.2-2.4 \%$ decrease in the ADG compared to pens with effective fly control. Some internal parasites, such as Ascaris suum, Trichuris suis and Oesophagostomum species, can also be found worldwide. In most cases the infestation has no clinical sings, thus remains unrecognizable, but the internal parasites deteriorate the production parameters in almost every production period, causing significant production losses. The Ascaris suum infection compared to an uninfected herd decreases the ADG by $2-9 \%$, and deteriorates the FCR by $5-13 \%$ for fatteners, the trichuriosis by $6-35 \%$ and $3-33 \%$, the strongylosis by $10-29 \%$ and $6-44 \%$, the stephanurosis by $25-$ $69 \%$ and $3-24 \%$, the hyostrongylosis by an average of $18 \%$ and $8 \%$, respectively, and the oesophagostomosis by $6-13 \%$ each. In the slaughterhouse the condemnation of liver with "milk spots" due to ascariosis might also cause severe economic losses. For suckling pigs the effective prophylaxis against coccidiosis is of fundamental importance in order to prevent the reduced growth rate, and both the pre- and post-weaning digestive disorders due to secondary infections causing deteriorative performance, consequently financial costs. After a proper metaphylaxis the number of suckling piglets having diarrhoea can be diminished by $83-98 \%$, that of mortalities by $53-63 \%$, the curative antibiotics cost for digestive disorders by $85-90 \%$, respectively, and ADG and FCR can also greatly improve in both the growing and fattening phase.
\end{abstract}

Keywords: swine, external parasites, internal parasites, coccidiosis, production impact
Volume 7 Issue 5 - 2018

\author{
László Ózsvári \\ University of Veterinary Medicine Budapest, Hungary
}

Correspondence: László Ózsvári, University of Veterinary Medicine Budapest ,P.O. Box. 2. Budapest 1400, Hungary, Tel: +36-I-478-4 I 85, Fax: +36-I-478-4186, Email: ozsvari.laszlo@univet.hu

Received: August 20, 2018 | Published: September 20, 2018

\begin{abstract}
Abbreviations: ADG, average daily gain; FCR, feed conversion ratio

\section{Introduction}

The herd health management is of importance in profitableness on swine farms, and their productivity can be improved with removal of pathogens. Surveys carried out in intensive swine units showed that the external and internal parasites in swine could have detrimental impact on production, thus, might result in considerable economic losses. Having assessed the production impact of parasitisms and coccidiosis in swine, the cost-benefit analysis of different antiparasitic treatments becomes possible. ${ }^{1,2}$
\end{abstract}

The most important harmful effects of the ectoparasitic infestations of swine are blood sucking, restlessness or decreased activity of the hosts, dermatitis, pruritus and the transmission of different pathogens, which ultimately result in decreased reproductive performance, reduced weight gain and feed conversion efficiency, and skin lesions at slaughter. ${ }^{3-10}$

The internal parasites of swine are still widespread, therefore every producer should be aware of their presence and the resulting losses. Several factors influence the amount of losses, of which the species of the endoparasites present, housing, management, feeding, geographical location and pig breed are the most important..$^{8-14}$ Despite the mainly subclinical infections, the economic importance of endoparasites originates from several sources: reduced fertility of sows, reduced feed intake and daily weight gain, lower feed conversion efficiency, lower lean meat proportion of the carcass, significant increase of the condemnation of lungs and liver, and in the clinical forms, if accompanied by other diseases, the mortality rate may increase significantly, as well. ${ }^{1,8,10,13,15-20}$

Therefore, the aim of this study is to review the major external and internal parasites in swine (including coccidiosis) and to gain a broader understanding to their impact on production parameters, especially ADG, FCR and mortality. This included a synthesis of current literature on the subject.

\section{Material and methods}

The literature search covered published journal articles, technical books, textbooks, university lecture notes and reports and was performed using the following methods:

i. Online search; Ebsco Discovery Service (EDS), Google scholar and Google web were searched for papers with "swine" or "pig" and "parasites" or "parasitism" or "coccidiosis" and "impact" or "production" or "loss" or "economic" or "cost-benefit".

ii. On-site literature search in the Ferenc Hutȳra Library, Archives and Museum at the University of Veterinary Medicine Budapest was conducetd with assistance of a librarian.

iii. Three experts in the field of swine parasitisms were asked to provide suitable publications.

iv. References of interest in indentified papers were reviewed.

v. Other relevant publications that the author was aware of were included.

Articles written in English or German or Hungarian were included. 
Articles were retained if they reported either original research or reviewed aspects of production impacts of parasitisms and coccidiosis in swine.

Using the framework proposed for livestock diseases by Rushton $^{21,22}$ all the direct disease impacts (either visible or invisible) of the major external and internal parasites in both breeding and fattening pigs were included in the review with special regard to $\mathrm{ADG}$ and FCR as the most important production parameters in swine fattening from an economic point of view. ${ }^{1}$

\section{Discussion}

\section{The effect of ectoparasites on production}

The most important ectoparasitic infestations influencing production parameters are mange caused by Sarcoptes scabiei var. suis and pediculosis caused by Haematopinus suis..$^{23-26}$

\section{Sarcoptic mange in pigs (Sarcoptes scabiei var. suis)}

Sarcoptic mange is the most important ectoparasitosis of swine worldwide, which is responsible for the highest economic losses among ectoparasitic infestations in swine production. Annual loss per sow was estimated at 100 EUR in Germany ${ }^{25}$ and 84-115 USD in the United States. ${ }^{27}$ The economic importance of this disease results from two factors: the majority of swine farms is infected worldwide (primarily subclinical mange), and the infestation influences the ADG and FCR of piglets and growing-finishing pigs. ${ }^{23,} 24,26,28-31$ Both the acute and chronic form of the disease lead to significant economic losses. ${ }^{25,27,32}$ The chronic form of sarcoptic mange in growing pigs occurs primarily among poor hygienic conditions, and on farms which do not have a prevention programme. In chronic mange, the ADG is significantly reduced, and the growth of the pigs is retarded. ${ }^{6,10,14}$ The subclinical form occurs on farms with better conditions. In this case the infection is maintained and transmitted mainly by sows and boars. Direct contact is the primary route of mange transmission, but contaminated bedding material and equipment of the pens can play a role, as well. ${ }^{25,33,34}$ (Figure 1) It has been proven, that the occurrence of mange is more frequent in winter, and the prevention programmes yield higher economic benefit in this season, too. ${ }^{25,26}$ The most important risk factors of the occurrence of mange infestation are the straw bedding to the farrowing pens (odds ratio: 15) and the imperfect separation of gestation and farrowing units. ${ }^{25}$

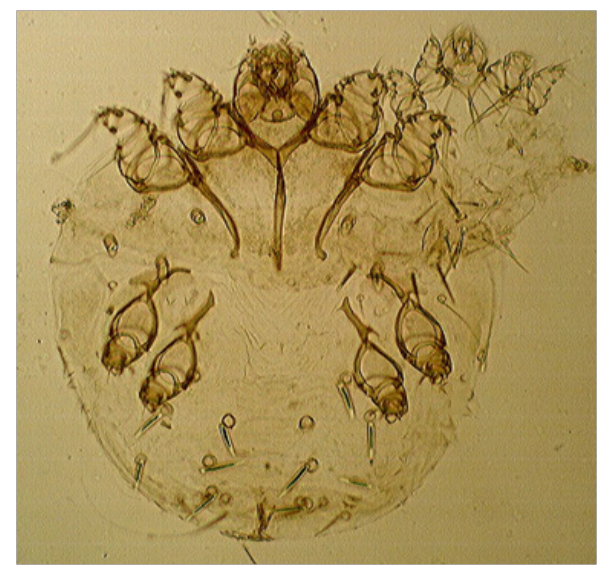

Photo G. Majoros

Figure I Female Sarcoptes with larves.
Sarcoptic mange can be eradicated by antiparasitic treatment, however, it is cheaper and more cost-effective to treat only animals with clinical signs, producers, therefore, choose this protocol more frequently. ${ }^{1,9,34}$ Mange can be effectively controlled by routine treatment of the sows before farrowing, thereby preventing the infection of the offspring, and by the treatment of newly introduced growing pigs, sows and boars during the quarantine. ${ }^{24,26,29,33}$ The cost of the eradication (drug and labour cost) is relatively easy to calculate, but to appraise the benefits stemming from the control of mange we have to know the production impact of the infestation. ${ }^{1,2}$ Many experiments show that the losses are correlated mainly with the intensity of the hypersensitivity reactions. Pruritus is a more important factor than the extent of skin lesions in the assessment of the reduction in performance. Skin lesions are considered to be not the cause, but the consequence of retarded growth. The largest losses occur in herds where the initial skin symptoms are accompanied by pruritic behaviour, but skin lesions as the result of intensive scratching and their secondary infections are absent. ${ }^{23,26,29}$

Scientific researches on the assessment of the economic importance of the mange yielded quite different results, so far. In the breeding period, the average number of weaned piglets per scabies infected sow reduced by one $(0.1-2.1)$ due to the crushing of piglets as a result of the pruritic behaviour. After antiparasitic treatment the incidence of piglet crushing reduced to half to one-third, culling of sows also decreased, and piglets of treated sows showed faster growth rate, the number of runt pigs diminished, and the sow feed consumption per weaned piglet or per kilogram live weight of weaned piglets decreased due to the larger litter weight at weaning. ${ }^{25-27,33}$ The results of the published field trials showed that ADG reduced by $11 \%$ on average (1-29\%), and FCR deteriorated by $6 \%(2-10 \%)$ in the fattening phase. Based on these studies, it is likely that FCR reflects the reduction in performance better than ADG. Condemnation and lower carcass value (due to papulae and abscesses) are also important loss sources. $23,24,26-28,30,31,33$

Beyond the direct losses, mange infestation causes indirect losses, as well. The most important sources of indirect loss are the physical damage of the equipment and installations related to scratching, and the increased susceptibility to other diseases. Infected herds are put to higher risk of secondary bacterial and mycotic skin infections, because these pathogens are capable of infecting via epidermal lesions. In several cases, the Staphylococcus infection could not be successfully treated in the growing phase, until the mange was present in the herd as a background disease. ${ }^{1,8,10,14,26,34}$

\section{Pediculosis in pigs caused by Haematopinus suis}

Low-intensity louse infestations do not cause a detectable deterioration in $\mathrm{ADG}$ and FCR. Infested weaned piglets show decreased activity, spend less time at the feeder, and move less, as well. Pruritic behaviour is caused in fattening pigs, which leads to skin damage; therefore the hide value is reduced. Additionally, hog lice are potential vectors of Mycoplasma (Eperythrozoon) suis. The risk of infection is significantly higher if gilts and dry sows are pastured (odds ratio: 13), and where high-pressure cleaning and chemical disinfection are not performed when the manure from nonlagoon systems is removed. ${ }^{4,5}$ (Figure 2)

\section{House flies and stable flies}

House flies (Musca domestica) and stable flies (Stomoxys calcitrans) mean serious indirect hazard in terms of epidemiology, occupational and public health, besides that their occurrence is very annoying. 
In particular, the role of the stable fly can be very important in the transmission of Mycoplasma suis. ${ }^{4,5}$ These parasites might reduce production performance directly due to the disturbance caused to the host, but based on the results of field trials, FCR is not affected, only ADG reduced by $1.3-2.4 \%$ compared to pens with effective fly control. $2,3,4,7$

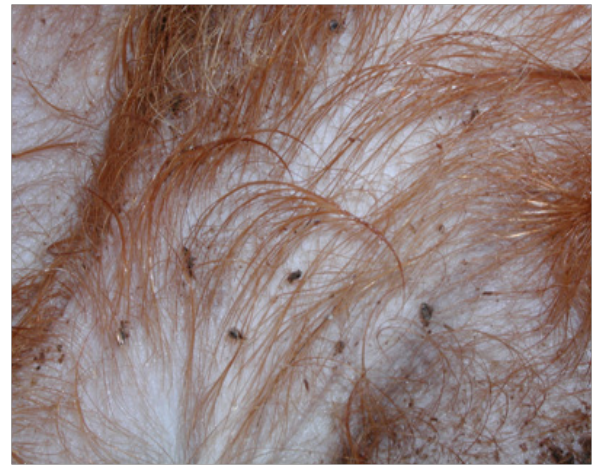

Photo I. Biksi

Figure 2 Haematopinus suis infestation in a pig.

\section{Flea infestation caused by Pulex irritans}

Flea infestation in pigs is of minor importance from an economic perspective, because only heavy infections cause intensive irritation. However, their role as a vector of Mycoplasma suis and swine pox virus must not be neglected. The allergic dermatitis similar to that of the dogs may occur, which can be confused with mange. ${ }^{2,5,10}$

\section{Tick infestations}

Tick infestations in pigs are caused by Ixodes, Dermacentor and Ornithodoros species, but their occurrence is exceptional in intensively managed pig herds. Their economic importance results from the disturbance caused to the host, and their role in the transmission of protozoal, rickettsial and viral diseases..$^{2,5,10}$

\section{The effect of internal parasites on production}

The economic losses caused by the internal parasites amounted to 3 USD per fattening pig in the USA, yet in 1977. The annual economic loss was 240 million USD on national level in 1981 in the US, not taking the losses due to condemnation into account. ${ }^{1,11}$ The metaanalysis of 18 scientific papers published in international journals between 1971 and 2009 was performed in order to assess the effects of experimental and naturally occurring endoparasitic infections on the production of fattening pigs. The statistical analyses showed that the daily feed intake reduced by $5 \%$, the ADG by $31 \%$, respectively and the FCR was $17 \%$ higher, on average, compared to the worm-free fattening pigs. ${ }^{18}$

The endoparasites of the largest importance in swine in the temperate zone are the large roundworms (Ascaris suum), the swine whipworms (Trichuris suis), and the nodular worms (Oesophagostomum spp.). Besides these endoparasites, the production may be significantly compromised in some herds by the red stomach worm (Hyostrongylus rubidus), the small intestinal threadworm (Strongyloides ransomi) and the swine kidney worm (Stephanurus dentatus) infections. ${ }^{2,13,35}$

\section{Large roundworm (Ascaris suum) infection}

Ascariosis is the most prevalent endoparasitosis of swine worldwide, being present in $50-75 \%$ of swine herds in most countries. It is the most important internal parasite infection from an economic point of view, as well. The disease may occur in any age group depending on the housing and management. On the conventional pig farms (which may even use straw bedding), ascariosis can be observed primarily in weaned and fattening pigs. On the wellmanaged intensive swine farms with good standard of hygiene, it becomes the most frequent in sows and boars. ${ }^{15,36-38}$ (Figure 3) The $A$. suum infection results in clinical signs rarely. Frequent coughing may indicate the acute phase of the infection, which is caused by the larvae migrating in the lungs of the host, thereby potentially exacerbating other diseases. No estimations are available on the losses caused by the migrating larvae at all. Even the clinically healthy pigs may harbour a large amount of adult ascarids, which cause production losses. The number of adult ascarids living in the host and the reduction in ADG are strongly correlated..$^{15,35-41}$

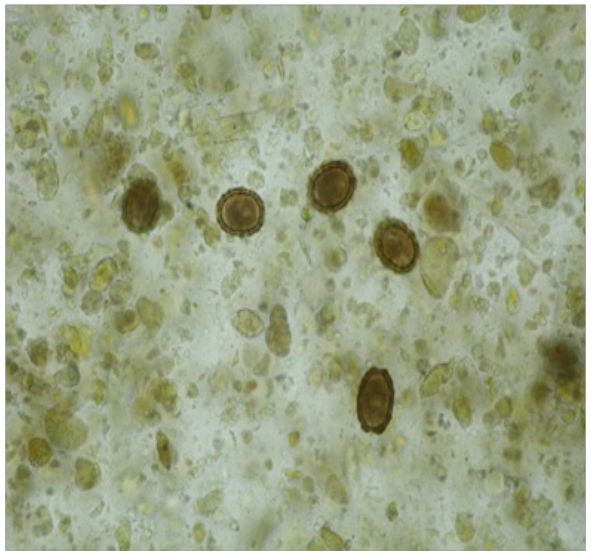

\section{Photo I. Biksi}

\section{Figure 3 Ascaris suum eggs.}

The economic losses caused by $A$. suum originate from the reduction in ADG, higher FCR and condemnation of the liver. In experimentally infected animals, the increase in the dose of $A$. suum eggs showed a negative linear correlation with ADG (2-9\%) and FCR (5-13\%) compared to control pigs. ${ }^{40}$

The aforementioned figures reflect experimental conditions, which may differ from the conditions of a pig farm. Field studies were conducted on Canadian and Danish swine farms, which concluded that the performance of fattening pigs was only mildly affected by ascarid infection (based on the quantification of faecal egg counts). Reduction of ADG was more pronounced in those cases, where the infection pressure was higher in the fattening phase, but no ascarids were found during the post mortem examinations in the slaughterhouse. The extent of ADG reduction was larger in the young fattening pigs, than its average in the whole fattening phase. ${ }^{17,18,37,39,41}$

The economic effect of migrating A. suum larvae stems from the liver condemnation due to "milk spots" (up to $41 \%$ of the livers may be condemned), which could mean heavy economic loss to the producers in the slaughterhouses..$^{15}$ A study conducted in Denmark reported that on farms not controlling ascariosis, "milk spots" were found in $10-33 \%$ of the livers. ${ }^{37}$ (Figure 4)

In the USA the higher FCR associated with mild ascariosis, and the increase in annual feed cost was estimated to be 155 million USD in $1987 .{ }^{11}$ In 2001 , the annual losses due to liver condemnation 
attributable to ascariosis were estimated at 17.5 million USD, whereas increased feed cost for fattening pigs caused 60.1 million USD losses per year. ${ }^{37}$

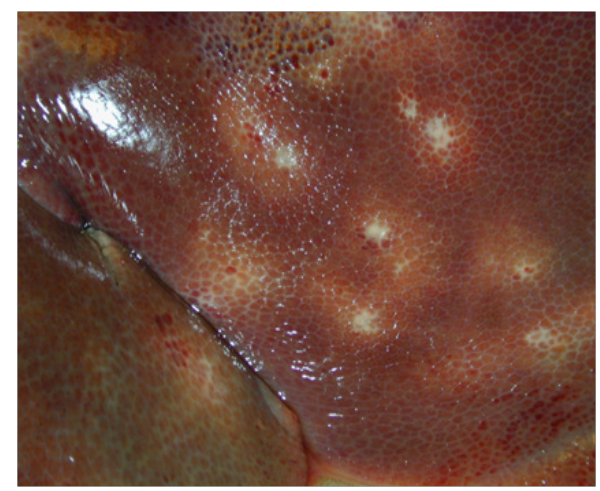

Photo Cs. Jakab

Figure 4 Pig liver with milk spots.

\section{Swine whipworm (Trischuris suis) infection}

The swine whipworm is a widespread endoparasite which lives in the large intestines and primarily in the caecum of the host. It consumes blood, and causes enteritis, diarrhoea, loss of appetite, which result in reduced growth, wasting and death of the infected animal. The ADG reduced by $6-35 \%$ and the FCR deteriorated by $3-33 \%$ in experimentally infected fattening pigs compared to wormfree controls. ${ }^{11,18,35,42}$

\section{Nodular worm (Oesophagostomum spp.) infection}

Oesophagostomosis is common in fattening pigs, while it is the most frequently occurring endoparasitic infection in sows and boars. ${ }^{35}$ The deterioration of production parameters was observed only in the first 21 days of the fattening in experimentally infected pigs: both ADG and FCR deteriorated by $6-13 \%$. The number of live newborn piglets decreased by 0.15 , and the average weight of the piglets was $0.3 \mathrm{~kg}$ smaller in infected sows. ${ }^{11,18,43}$

\section{Red stomach worm (Hyostrongylus rubidus) infection}

H. rubidus is a blood-sucking internal parasite living in the stomach of the host, causing clinical or subclinical infection..$^{35}$ ADG reduced by $18 \%$, whereas FCR decreased by $8 \%$ in experimentally infected fattening pigs compared to controls. ${ }^{11,18,44}$

\section{Small intestinal threadworm (Strongyloides ransomi) infection}

S. ransomi is most common in warm climate regions, but the infection occurs in suckling pigs in moderate climate regions, as well, which are infected via the intact skin or via colostrums. ${ }^{35}$ Experimental infections showed a linear correlation between the dose of infection and the main parameters in the fattening phase. Depending on the dose of infection, ADG reduced by $10-29 \%$ and FCR increased by $6-44 \%$ compared to control animals. ${ }^{11,18,45}$

\section{Swine kidney worm (Stephanurus dentatus) infection}

$S$. dentatus is responsible for a significant proportion of liver condemnations besides ascarids in the USA. The kidney worm infection has not been detected in many European countries yet, but introduction of the disease cannot be ruled out. ${ }^{35}$ ADG reduced by $25-$
$69 \%$, whereas FCR deteriorated by $3-24 \%$ in experimentally infected pigs. ${ }^{11,18,46}$

\section{The effect of pig coccidiosis on production}

Coccidiosis is one of the most frequent causes of diarrhoea in piglets, and Isospora suis is one of the most prevalent pathogens in intensive pig farming systems. The results of international, mainly Western-European studies showed that coccidiosis is present on 75$76 \%$ of the pig farms, and $40-100 \%$ of the piglets on a farm may be infected irrespective of the hygienic circumstances. Studies conducted in the mid-2000s showed that $44 \%$ of the pig farms was infected (without clinical signs on many farms!), and the within-herd prevalence was $10-90 \%$ based on faecal sample examination. ${ }^{47,48}$ (Figure 5) The clinical signs of coccidiosis appear minimum 2-4 days after infection in 2-3 weeks old piglets, and the diarrhoea lasts for 3-4 days. ${ }^{47}$ Coccidiosis damages the intestinal mucosa and impairs intestinal function, therefore, the ADG of piglets decreases. The reduction in weight gain may reach 1000 grams until weaning even in the subclinically infected animals. ${ }^{48,49}$ These effects impair ADG in the entire growing-finishing phase, thereby extending the fattening period and reducing annual income. In addition, the deteriorated FCR after weaning increases feed cost. ${ }^{48,50-52}$ Coccidiosis results in increased mortality, and if mixed with secondary viral (eg. rotavirus, adenovirus) and mainly bacterial (e.g. Clostridium perfringens, E. coli, Salmonella spp.) infections, it may cause high mortality rate before weaning, especially in herds where simultaneous infection with $C$. perfringens and $I$. suis occurs soon after birth. ${ }^{53}$ Obviously, the treatment of diarrhoea caused by secondary infections results in increased antibiotic use, and, therefore, in larger drug cost.

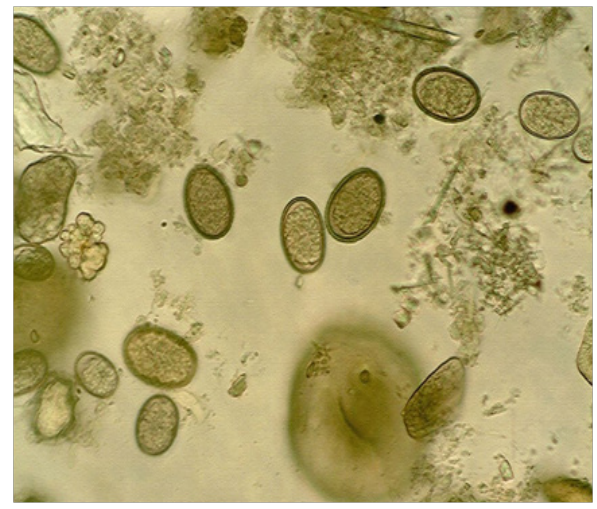

Photo G. Majoros

Figure 5 Isospora suis eggs.

The results of laboratory and field trials to date show that metaphylactic treatment at the age of 1-5 days decreases the occurrence of diarrhoea by $83-98 \%$, the cost of antibiotics used for treatment of diarrhoea reduces by $85-90 \%$, and mortality rate is lowered by $53-$ $63 \% .^{48,50-52}$ Besides, Lawsonia intracellularis positivity was much lower in treated pigs aged 56-105 days than in non-treated (control) animals. ${ }^{49}$ Furthermore, ADG improves significantly, treated pigs are more uniform at weaning, and weigh $0.5-1.4 \mathrm{~kg}$ more, depending on the infection pressure and the time of weaning (which means an increase in ADG of 25 grams on average). The difference in live weight can reach $0.8-3.5 \mathrm{~kg}$ by the end of the growing phase (at the same time FCR improves by $8.5 \%$, on average). Consequently, a 3-5.4 kg larger slaughter weight is achieved in a 5-12 days shorter fattening phase. ${ }^{48,50-52}$ 


\section{Cost-benefit analysis of antiparasitic treatments}

The first step in the cost-benefit analysis of preventive antiparasitic treatments and of metaphylactic treatment of coccidiosis is the calculation of herd-level economic losses. The following data have to be acquired: (1) the within-herd prevalence of ecto- and endoparasitic infections, and that of the different forms of coccidiosis; (2) the extent of deterioration in the production parameters influenced by the parasitic or coccidial infections; and finallly (3) summation of the economic consequences due to the affected production parameters. ${ }^{1,8,9}$

The prevalence of parasitic and coccidial infections can be assessed by herd diagnostic tests. Thereafter, the change in production parameters (in the nursery and in the fattening phase: mortality, ADG and FCR) can be relatively accurately quantified based on the results of field trials, but the lack of them can be estimated fairly well by using literature data. The findings of this paper can help the swine health professionals to assess the economic impact of parasitisims and coccisidiosis, and to convince the farm managers to control these diseases. Naturally, the possibility of multiple infections with several parasite species and I. suis should be taken into account among field conditions. This makes the estimation of overall production losses attributable to parasitic infections a little bit more difficult, particularly, because of the interactions among pathogens. ${ }^{1,8,9}$ The additional revenue due to the suppression of the infection can be calculated based on the expected improvement of production parameters as a result of the treatment. The profit of the treatment can be calculated by comparing the additional revenue and the treatment costs. In most cases under field conditions, only the lowered feed cost is considered, which yields misleading results, since the additional revenue of producing more finishers must not be neglected. Of course, the amount of extra profit per slaughter pig greatly depends on the farm conditions, the feed costs and the price of finished pigs. ${ }^{1,2,21,53}$

\section{Conclusion}

Antiparasitic treatments exert their effects in two ways: firstly, the host gets rid of the parasites and their harmful effects instantly; secondly, the herd will be exposed to the infection pressure caused by eggs, larvae, etc. living in the environment to a much lesser extent. Results from the literature consistently confirmed that the occurrence of ecto- (especially the mange) and endo parasites (particularly the ascarids), and I. suis can significantly deteriorate the poduction parameters of swine breeding and fattening (especially ADG and FCR), and therefore, profitability. Thus, antiparasitic control programs may result in significant improvement of production parameters and can be beneficial from an economic point of view.

\section{Acknowledgements}

This paper was supported by the European Union and co-financed by the European Social Fund (grant agreement no. EFOP-3.6.1-162016-00024, project title: Innovations for intelligent specialization on the University of Veterinary Science and the Faculty of Agricultural and Food Sciences of the Széchenyi István University cooperation). This research was also supported by the 17896-4/2018/FEKUTSTRAT grant of the Hungarian Ministry of Human Capacities.

\section{Conflict of interest}

The author declares that there is no conflict of interest.

\section{References}

1. Bíró O, Ózsvári L. Animal Health Economics. University Lecture Notes (in Hungarian). SZIU FVS. 2006;1-161.

2. Dijkhuizen AA, Morris RS. Animal Health Economics. Sydney; 1997.

3. Campbell JB, Boxler DJ. Effects of house and stable flies (Dipteria Muscidae) on weight-gain and feed-effeciency by feeder pigs. Southwest Entomol.1984;9:273-274.

4. Davis DP, Williams RE. Influence of hog lice, Haematopinus suis, on blood components, behavior, weight-gain and feed-effeciency of pigs. Vet Parasitol.1986;22(3-4):307-314.

5. Farkas R. Veterinary parasitology III. Arachnoentomology. Hungary: Budapest; 2006:1-101.

6. Matthes W, Ilchmann G, Rehbock F. Economic impact of subclinical parasitic infestations in fattening pigs. Prakt Tierarzt.1998;79:1067-68.

7. Moon RD, Jacobson LD, Cornelius SG. Stable flies (Dipteria, Muscidae) and productivity of confined nursery pigs. J Econ Entomol.1987;80:1025-27.

8. Morris RS, Meek AH. Measurement and evaluation of the economic effects of parasitic disease. Vet Parasitol.1980;6:165-184.

9. Perry BD, Randolph TF. Improving the assessment of the economic impact of parasitic diseases and of their control in production animals. Vet Parasitol.1999;84:145-168.

10. Sykes AR. Parasitism and production in farm animals. Anim Prod.1994;59:155-172.

11. Stewart TB, Hale OM. Losses to internal parasites in swine production J Anim Sci.1988;66:1548-1554.

12. Roepstorff A, Mejer H. Helminth parasites in pigs: New challenges in pig production and current research highlights. Vet Parasitol.2011;180:72-81.

13. Roepstorff A, Nansen P. Epidemiology, diagnosis and control of helminth parasites of swine. Animal Health Manual. FAO. 1998;1-161.

14. Thamsborg SM, Roepstorff A, Larsen M. Integrated and biological control of parasites in organic and conventional production systems. Vet Parasitol.1999;84:169-186.

15. Kurze S, Wesemeier HH. Ascaridiasis and discarded livers in pigs - data from veterinary practice and economic consequences. Prakt Tierarzt. 2006;87:128-133.

16. Pattison HD, Smith WC, Thomas RJ. Effect of subclinical Nematode parasitism on reproductive performance in the sow. Anim Prod.1979;29:321-326.

17. Urban JF, Romanowski RD, Steele NC. Influence of helminth parasite exposure and strategic application of anthelmintics on the development of immunity and growth of swine. J Anim Sci.1989;67:1668-1677.

18. Kipper M, Andretta I. Meta-analysis of the effects of endoparasites on pig performance. Vet Parasitol.2011;184:316-320.

19. Knecht D, Popiołek M, Zaleśny G. Does meatiness of pigs depend on the level of gastro-intestinal parasites infection. Prev Vet Med.2011;99:234-239.

20. Knecht D, Jankowska A, Zaleśny G. The impact of gastrointestinal parasites infection on slaughter efficiency in pigs. Vet Parasitol.2012;184:291-297.

21. Rushton J. The Economics of Animal Health and Production. CABI. 2009:1-364. 
22. Rushton J. Improving the use of economics in animal health - Challenges in research, policy and education. Prev Vet Med. 2017;137:130-139.

23. Cargill CF, Dobson KJ. Experimental Sarcoptes scabiei infestation in pigs. 2. Effects on production. Vet Rec.1979;104:33-36.

24. Dalton PM, Ryan WG. Productivity effects of pig mange and control with ivermectin. Vet Rec.1988;122:307-308.

25. Damriyasa IM, Failing K. Prevalence, risk factors and economic importance of infestations with Sarcoptes scabiei and Haematopinus suis in sows of pig breeding farms in Hesse. Med Vet Entomol.2004;18:361-367.

26. Davies PR. Sarcoptic mange and production performance of swine-A review of the literature and studies of associations between mite infestation, growth rate and measures of mange severity in growing pigs. Vet Parasitol.1995;60:3-4.

27. Arends JJ, Stanislaw CM, Gerdon D. Effects of sarcoptic mange on lactating swine and growing pigs. J Anim Sci.1990;68:1495-1499.

28. Alva-Valdes R, Wallace DH. The effects of sarcoptic mange on the productivity on confined pigs. Vet Med-US.1986;81:258-260.

29. Elbers ARW, Rambags PGM et al. Production performance and pruritic behaviour of pigs naturally infected by Sarcoptes scabiei var. suis in a contact transmission experiment. Vet Quart. 2000;22:145-149.

30. Wooten E, Blecha F. The effect of sarcoptic mange on growth performance, leucocytes and lymphocyte proliferative responses in pigs. Vet Parasitol.1986;22:315-324.

31. Wooten Saadi E, Broce AB. Growth performance and behavioral patterns of pigs infested with sarcoptic mites (Acari, Sarcoptidae). J Econ Entomol. 1987;80:625-628.

32. Ronald BSM, Senthilkumar S, Sivakumar T. Economic loss due to Sarcoptes scabiei in large white Yorkshire pigs. Indian Vet J. 2005;82:1120-1121.

33. Mercier P, Cargill CF, White CR. Preventing transmission of sarcoptic mange from sows to their offspring by injection of ivermectin - Effects on swine production. Vet Parasitol. 2002;110:25-33.

34. Rambags, P. Mange-free hog farms - Sanitation concepts, certification approaches and cost-benefit analyses. Prakt Tierarzt. 2004;85:198-200.

35. Kassai T. Helminthology (in Hungarian): Textbook. Budapest, Hungary: MÁOK; 2011.

36. Thamsborg SM, Nejsum P, Mejer H. Impact of Ascaris suum in livestock. In: Holland C, Editor. Ascaris: The Neglected Parasite. Dublin, Ireland: Elsevier; 2013:363-381.

37. Boes J, Kanora A. Effect of Ascaris suum infection on performance of fattening pigs. Vet Parasitol.2010;172:269-276.

38. Del Pozo Sacristán R, Beek J. Associations between Ascaris suum infections and different farm management practices. Poceedings 24th
IPVS Congress and 8th ESPHM, 7-10 June 2016; Dublin, Ireland; 164 p.

39. Bernardo TM, Dohoo IR, Donald A. Effect of ascariasis and respiratory diseases on growth rate in swine. Can J Vet Res.1990;54:278-284.

40. Hale OM, Stewart TB, Marti OG. Influence of an experimental infection of Ascaris suum on performance of pigs. J Anim Sci.1985;60(1):220 225.

41. Stewart TB, Leon DL. Performance of pigs with mixed Nematode infections before and after ivermectin treatment. Vet Parasitol.1991;39(3-4):253-266.

42. Hale OM, Stewart TB. Influence of an experimental infection of Trichuris suis on performance of pigs. J Anim Sci.1979;49(4):1000-1005.

43. Hale OM, Stewart TB. Influence of an experimental infection of nodular worms (Oesophagostomum spp.) on performance of pigs. $J$ Anim Sci.1981;52:316-322.

44. Castelin JB, Herbert IV, Lean IJ. Live-weight gain of growing pigs experimentally infected with massive doses of Hyostrongylus rubidus (Nematoda) larvae. Brit Vet J. 1970;126:579-582.

45. Hale OM, Marti OG. Influence of an experimental infection of Strongiloides ransomi on performance of pigs. J Anim Sci. 1984;58(5):1231-1235.

46. Hale OM, Marti OG. Influence of an experimental infection of swine kidneyworm (phanuruStes dentatus) on performance of pigs. J Anim Sci. 1983;56(3):616-620.

47. Farkas R, Szeidemann Zs, Majoros G. Isospora suis (Apicomplexa: Eimeriidae) infection of suckling piglets. Literature review and own research (in Hungarian). Magy Állatorv Lapja. 2005;127:368-375.

48. Maes D, Vyt P. Effects of toltrazuril on the growth of piglets in herds without clinical isosporosis. Vet J. 2007;173(1):197-199.

49. Kreiner T, Worliczek HL. Influence of toltrazuril treatment on parasitological parameters and health performance of piglets in the field. An Austrian experience. Vet Parasitol. 2011;183(1-2):14-20.

50. Joachim A, Mundt HC. Efficacy of sulfonamides and Baycox ${ }^{\circledR}$ against Isospora suis in experimental infections of suckling piglets. Parasitol Res. 2011;109(6):1653-1659.

51. Scala A, Demontis F. Toltrazuril and sulphonamide treatment against Isospora suis infected sukcling piglets: Is there an actual profit. Vet Parasitol. 2009;163(4):362-365.

52. Scampardonis V, Sotiraki S. Effect of toltrazuril in nursing piglets naturally infected with Isospora suis. Vet Parasitol. 2010;172(1-2):4652.

53. Mengel H, Kruger M. Necrotic enteritis due to simultaneous infection with Isospora suis and clostridia in newborn piglets and its prevention by early treatment with toltrazuril. Parasitol Res. 2012;110(4):72-78. 